\title{
O Outro e a Escola: análise relacional dos Parâmetros Curriculares e do Discurso de Professores/as em Foz do Iguaçu, Paraná, Brasil
}

\author{
El Otro y la Escuela: análisis relacional de los Parámetros \\ Curriculares y el Discurso de Profesores/as en Foz de Iguaçu, \\ Paraná, Brasil
}

\section{The Other and the School: a relational analysis of Curriculum Parameters and the Teachers' Discourse in Foz do Iguaçu, Paraná, Brazil}

\author{
Rafael Giovanetti Teixeira ${ }^{1}$ \\ Laura Janaina Amato²
}

\begin{abstract}
Resumo
Amparado pelo projeto de iniciação científica "Construção do Imaginário trinacional”, orientado pela professora Laura Janaina Dias Amato, o presente trabalho analisa de maneira relacional: o discurso de professores/as em classes de nível fundamental um - de primeiro a quinto ano - da rede de educação pública de Foz do Iguaçu, Paraná, Brasil; os projetos político pedagógicos dessas escolas; e os temas transversais dos Parâmetros Curriculares Nacionais, tendo como enfoque as relações de alteridade, no que diz respeito a diferenças de classe, cultura, raçaletnia, gênero, nacionalidade e língua. O objetivo é compreender a atuação da escola nas dinâmicas de formação do sujeito em sua relação com o "outro", a partir de métodos etnográficos como mecanismos de investigação, realizado em uma escola da cidade. Conclui-se que há consonância entre o discurso dos professores observados e o projeto político pedagógico analisado, porém estão distanciados dos parâmetros curriculares e da realidade sociocultural em que a escola está situada.
\end{abstract}

Palavras-Chave: Alteridade; Cultura; Currículo; Discurso; Educação; Escola.

\section{Resumen}

Amparado por el proyecto de iniciación científica "Construcción del Imaginario Trinacional" orientado por la profesora Laura Janaina Amato, el presente trabajo analiza de manera relacional: el discurso de profesores/as en clases de nivel fundamental uno - de primer a quinto año - de la red de educación pública de Foz do Iguaçu, Paraná, Brasil; los proyectos políticos pedagógicos de esas escuelas; y los temas transversales de los

\footnotetext{
${ }^{1}$ Graduando em Ciência Política e Sociologia; Instituto Latino-Americano de Economia, Sociedade e Política ILAESP; Foz do Iguaçu, Paraná, Brasil; rafael.teixeira@aluno.unila.edu.br.

${ }^{2}$ Doutorado em Letras pela Universidade Federal do Paraná (2012); Instituto Latino-Americano de Arte, Cultura e Histórica - ILAACH; Foz do Iguaçu, Paraná, Brasil; laura.amato@unila.edu.br.
} 
Parámetros Curriculares Nacionales, teniendo como enfoque las relaciones de alteridad, en las dimensiones de clase, cultura, razaletnia, genero, nacionalidad, y lengua. El objetivo es comprender la actuación de la escuela en las dinámicas de formación del sujeto en su relación con el otro, a partir de métodos etnográficos como mecanismos de investigación, realizados en una escuela de la ciudad. Se concluye que hay consonancia entre el discurso de los profesores observados y el proyecto político pedagógico analizado, pero están distanciados de los parámetros curriculares y de la realidad sociocultural en que se encuentra la escuela.

Palabras claves: Alteridad; Cultura; Currículo; Discurso; Educación; Escuela.

\section{Abstract}

Based on the scientific initiation project "Construction of the Trinational Imaginary" guided by Professor Laura Janaina Amato, the present work analyzes relationally: the discourse of teachers in fundamental level classes one - from first to fifth year - of the Public education network in Foz do Iguaçu, Paraná, Brazil; The political pedagogical projects of these schools; And the cross-cutting themes of the National Curricular Parameters, focusing on the relations of otherness in the dimensions of class, culture, race / ethnicity, gender, nationality, and language. The objective is to understand the performance of the school in the dynamics of the formation of the subject in their relationship with the other, based on ethnographic methods as research mechanisms, carried out in a school in the city. It is concluded that there is a consonance between the teachers' discourse observed and the political pedagogical project analyzed, but they are distanced from the curricular parameters and the sociocultural reality of the school.

Keywords: Alterity; Culture; Curriculum; Education; School; Speech.

\section{Introdução}

A cidade de Foz do Iguaçu está localizada no extremo oeste do Estado do Paraná na região Sul do Brasil, faz fronteira com Ciudad del Este do Paraguai e Puerto Iguazú da Argentina. Com aproximadamente 270.000 habitantes, é um dos principais destinos turísticos do país, que aumenta, durante todo ano, sua diversidade étnica, cultural e linguística. Segundo site da prefeitura há aproximadamente 80 nacionalidades que convivem baixo as dinâmicas da cidade, voltadas principalmente ao comercio e ao turismo.

As pontes que sobrepujam as limitações geográfico-aquáticas entre os três países apresentam um primeiro passo para a problematização das questões relacionadas às suas fronteiras políticas e, principalmente, para suas limitações enquanto fronteiras culturais e de identificação nacional, nesse local de intenso trânsito e fluxo de pessoas e mercadorias que confronta o discurso de identidade nacional.

Por trás das atrações turísticas, a cidade também apresenta periferias, bairros afastados, ocupações urbanas, com pessoas em vulnerabilidade socioeconômica. Essas regiões também mantem a diversidade da região de fronteira (senão forem a maior expressão dela) ao acolherem migrantes e imigrantes das regiões vizinhas e de diversas localidades nacionais e internacionais. As escolas desses bairros, que já em sua singularidade municipal, também 
apresentam alunos e alunas em tamanha variedade cultural, étnica e linguística, também contam com o desafio socioeconômico para lidar com as crianças.

\section{O outro e a escola}

O trabalho de campo buscou como referencial empírico uma escola municipal nas proximidades da fronteira com a Argentina. A dificuldade de contato e disponibilidade com as escolas da cidade para acolher um participante externo as suas atividades foi suplantada pelo contato prévio que essa escola tem com a UNILA em projetos realizados em parceria, que serão retomados mais a frente.

Optou-se pelo trabalho de campo e principalmente pela observação participante, pelo maior contato com a realidade da escola, tanto nas salas de aula, quanto na convivência com os/as professores/as - diz-se sala dos professores. Mais do que tudo, o objetivo da observação participante:

[...] ha sido detectar los contextos y situaciones en los cuales se expresan y generan los universos culturales y sociales, en su compleja articulación y variabilidad. La aplicación de esta técnica o, mejor dicho, conceptualizar esta serie de actividades como una técnica para obtener información, se basa en el supuesto de que la presencia -esto es, la percepción y la experiencia directas-ante los hechos de la vida cotidiana de la población en estudio -con sus niveles de explicitación - garantiza, por una parte, la confiabilidad de los datos recogidos y, por la otra, el aprendizaje de los sentidos que subyacen tras las actividades de dicha población. La experiencia y la testificación se convierten, así, en "la" fuente de conocimiento del antropólogo. (GUBER, 2004, p.172).

A inserção no campo aconteceu pelo intermédio da coordenadora pedagógica da escola, que distribuiu professores e classes de acordo com seus critérios, considerando quais estariam dispostos a acolher um observador a mais na sala de aula. Foi apresentado que a pesquisa trataria da observação dos estudantes estrangeiros nas salas na escola e das relações culturais.

Para melhor aproximação com os/as professores/as e para garantir a maior naturalidade possível do ambiente, tanto na sala de aula quanto na sala dos professores, excluiu-se a utilização do gravador de voz e do registro em caderno de campo durante os acontecimentos, entre outras, pelas dificuldades do

[...] investigador ante el dilema de atender y mirar al informante o tomar notas; en el curso de la entrevista, el registro escrito puede incomodar al informante, quien puede optar por empezar a dictarle al investigador; en vez de expresarse más espontáneamente. Por otra parte, el contacto visual es fundamental para establecer una relación de confianza, proximidad y soltura, marco conveniente para desarrollar buenas entrevistas. (GUBER, 2004, p.254). 
Desta maneira, optou-se pelo registro posterior ao campo, registrando tudo "lo que le parezca, todo lo que recuerde, y establecer luego las relaciones y no relaciones (es decir, aquello que reconoce como significativo y aquello cuya relevancia todavía no vislumbra) con su objeto de investigación." (GUBER, 2004, p. 258). É evidente que já havia enfoques na observação e na cognição que guiaram a observação, mas a contribuição do campo foi enorme para guiar a pesquisa.

Os debates sobre educação e cultura serviram de base teórica para a entrada no campo. A pluralidade cultural é de grande debate na área da educação, pelo seu histórico homogeneizante, por ser "el espacio de construcción y reproducción de valores, actitudes e identidades y del poder histórico-hegemónico del Estado" (WALSH, 2009, p.5). Há nesse sentido, vários debates de como se deve tratar essa pluralidade cultural na educação.

As inúmeras discussões acadêmicas em seus prefixos pluri, multi, e inter-cultural abordados e discutidos no limiar da produção do conhecimento e militância (se é que se pode separá-los) são demandas da realidade de grupos discriminados e excluídos e de movimentos sociais referentes a questões de identidade.

Fleuri (2000, p.48 e 49) retoma de maneira sintética e comparada as formas de se elaborar o conhecimento no mundo da pesquisa e da educação no debate monoculturalismomulticulturalismo. Para este autor, de um lado, o monoculturalismo entende que todos os povos e grupos compartilham, em condições equivalentes, de uma cultural universal; de outro lado, o multiculturalismo reconhece que cada povo e cada grupo social desenvolve historicamente uma identidade e uma cultura próprias; considera que cada cultura é válida em si mesma, na medida em que corresponde às necessidades e às opções de uma coletividade. E propõe uma terceira perspectiva, a abordagem intercultural, que além de reconhecer o sentido e a identidade cultural de cada grupo social, valoriza o potencial educativo dos conflitos e busca desenvolver a interação e reciprocidade entre grupos diferentes, como fator de crescimento cultural e de enriquecimento mútuo.

Essas dimensões, tanto a intercultural, como o monoculturalismo e o multiculturalismo, são abordadas e adotadas de maneira específica de acordo com a realidade social em que está inserida. Catherine Walsh (2009) estabelece a compreensão de interculturalidade desde América Latina, reconhecendo suas especificidades. Para essa autora (2009, p.2) esse movimento estabelece uma nova atenção à diversidade étnico-cultural, que 
parte do reconhecimento jurídico e de uma necessidade de promover relações positivas entre distintos grupos culturais e de combater a discriminação, o racismo e a exclusão.

Mesmo na conjuntura específica de América Latina, há maneiras distintas que este trabalho intercultural é feito. Walsh, (2009, p.2 e 3) reconhece três tipos de abordagens: a abordagem intercultura relacional, que faz referência de forma mais básica e geral ao contato e intercambio entre culturas, e nesse sentido, minimiza o conflito e os contextos de poder, dominação e colonialidade contínuas na América Latina; a abordagem funcional que estabelece metas à inclusão da diversidade e diferenças culturais ao interior da estrutura social estabelecida; e a abordagem intercultural crítica, como projeto a se construir, que não parte da diversidade ou diferenças culturais, mas do "problema estrutural-colonial-racial", do reconhecimento de que a diferença se constrói dentro de uma estrutura matriz colonial de poder racializado, hierarquizado, com os brancos ou "branqueados" em cima dos "povos indígenas e afrodescendentes nos planos inferiores" (WALSH, 2009, p.4).

De uma maneira histórica, Fleuri (2003, p.18) destaca que Declaração sobre a raça e os preconceitos raciais, aprovada e proclamada pela Conferência Geral da Organização das Nações Unidas para a Educação, a Ciência e a Cultura (UNESCO) em 1978, foi um dos primeiros textos a propor os conceitos fundantes da educação intercultural ao propor uma educação para a paz e de prevenção para o racismo.

No Brasil, a Constituição Federal de 1988 "passou a assegurar o direito das comunidades indígenas a uma educação escolar diferenciada, específica, intercultural e bilíngüe. Os índios deixaram de ser considerados categoria social em vias de extinção e passaram a ser respeitados como grupos étnicos diferenciados, com direito a manter sua organização social, costumes, línguas, crenças e tradições”. (FLEURI, 2003, p.21). E em 1997, o Ministério da Educação lançou os Parâmetros Curriculares Nacionais como proposta a direcionar toda educação do ensino fundamental no país, onde constam os temas transversais: ética, saúde, meio ambiente, orientação sexual e pluralidade cultural.

Esses Parâmetros elegem a "cidadania como eixo vertebrador da educação escolar" (BRASIL, 1997, p.23) e estabelecem os temas transversais a partir de quatro critérios centrais: urgência social; abrangência nacional; possibilidade de ensino e aprendizagem no ensino fundamental; e favorecer a compreensão da realidade e a participação social. Os temas transversais devem ser abordados de maneira interdisciplinar, complementando o conteúdo das disciplinas, desde história e geografia até matemática. Entre estes, a urgência social 
aparece principalmente o racismo latente no mito da democracia racial, apresentado na justificativa do documento de pluralidade cultural:

Historicamente, registra-se dificuldade para se lidar com a temática do preconceito e da discriminação racial/étnica. O País evitou o tema por muito tempo, sendo marcado por "mitos" que veicularam uma imagem de um Brasil homogêneo, sem diferenças, ou, em outra hipótese, promotor de uma suposta "democracia racial". Na escola, muitas vezes, há manifestações de racismo, discriminação social e étnica, por parte de professores, de alunos, da equipe escolar, ainda que de maneira involuntária ou inconsciente. (BRASIL, 1997, p.20)

A demanda social existe há muito tempo, a urgência é inadiável. Esta proposta considera, do ponto de vista social, os movimentos que há tanto lutam por essa valorização [da pluralidade cultural]. O grande desafio proposto para a educação é estabelecer conexões entre o que se aprende na escola e a vida da população brasileira. (BRASIL, 1997, p.21)

Tendo em vista, esses debates sobre cultura e educação, suas terminologias e estruturações nos Parâmetros Curriculares Nacionais, deu-se início ao trabalho de campo. Como foi mencionado, entre as limitações disponibilidade das escolas, o trabalho de campo aconteceu nos dias: cinco de junho de dois mil e dezessete, no período da manhã, acompanhando a turma do quarto ano do nível fundamental, das classes de matemática e história/geografia, com professores diferentes; e no dia seis de junho de dois mil e dezessete, durante o período da manhã e da tarde, acompanhando a turma do segundo ano do nível fundamental, na classe de português, com a mesma professora.

Porém, o possível questionamento tanto da quantidade de dias acompanhados, como da variedade de turmas - feitos também por este pesquisador - foi suplantado no campo quando, na sala dos professores, no intervalo de turnos, ao observar o diálogo de duas professoras, indagando suas preferências em lecionar para as turmas iniciantes ou as para as maiores. As duas professoras tinham preferencias opostas, a primeira buscava as turmas do primeiro e segundo ano, no máximo até o terceiro, já a segunda buscava as turmas do quarto e quinto ano, chegando até o terceiro também. Uma argumentava que o comportamento das crianças muda muito quando vão crescendo, aumentando em agitação e desobediência sendo que as crianças menores eram mais fáceis de tratar, ensinando-as desde o começo; a outra, de maneira oposta, sustentava que as crianças muito novas não rendiam no ensino, precisando repetir muito as atividades, sendo as maiores mais "espertinhas" (em suas palavras) e melhores para acompanhar o conteúdo. Tendo em vista o apresentado, o acompanhamento das turmas do segundo e quarto ano fica no intermédio desse debate, permitindo observar o quanto do discutido por elas varia nas salas. O convívio na sala dos professores também possibilitou grande riqueza pelos seus comentários, tanto os observados, em diálogos entre si, quanto os participantes, sobre as crianças e as dificuldades no ensino. 
Logo ao chegar à sala dos professores, no primeiro dia de campo, uma professora recém-formada destaca: "Na teoria é muito lindo, mas na hora da prática a gente vê como é." Mas que teoria? Qual prática? A observação em sala apresentou algumas pistas.

Aula de matemática, quarto ano, professor branco, entre cinquenta e sessenta anos, tom de voz moderado; conteúdo escrito no quadro, de perguntas e respostas - escrever números por extenso, adição e subtração e atividade temática genérica (papai construiu um muro em 28 dias, quantas semanas levaram?) - sem vinculação com a realidade das crianças ou com os temas transversais.

Aula de história/geografia com essa mesma turma, professora branca, entre 30 e 40 anos, tom de voz elevado; aula de revisão para a prova - perguntas e respostas em questões de múltipla escolha, temáticas do nacional ao estadual e municipal relacionadas aos textos colados no caderno, relação conteúdista do conhecimento (Qual foi o primeiro nome da cidade de Foz do Iguaçu? Em qual formação geográfica está situada a cidade?) sem vinculação com os Temas Transversais. Nesta turma, não havia estudantes de outras nacionalidades.

Turma segundo ano, aula de português, turno da manhã, professora branca, entre cinquenta e sessenta anos, tom de voz elevado; atividade no quadro de escrita, leitura e interpretação com temática genérica (A boneca de Ana...), sem ligação com os temas transversais nem com a realidade social das crianças. Nesta turma, havia uma aluna paraguaia, repetente, com problemas de aprendizagem. A mesma atividade foi realizada na turma do segundo ano da tarde. Nesta, havia dois alunos não-brasileiros, um argentino e um paraguaio.

A dificuldade desses professores em passar todo conteúdo programado foi percebida em todas as turmas e também esteve presente em suas falas. O professor de matemática logo após passar a atividade no quadro, comenta em particular e em baixo tom: "Nossa clientela aqui na escola é muito fraca, nessa sala de 32, salva 7 que consegue acompanhar mesmo". A professora de história/geografia também comentou em particular que não consegue trabalhar todo material que gostaria porque os alunos não acompanham. A professora de português, por sua vez, comparou as duas turmas sendo a da manhã como a "problemática" e a da tarde como a "melhor" por acompanhar o programa.

Vinculada ao rendimento da turma ou diretamente ao de algumas crianças, o comentário à situação familiar das crianças e ao cenário socioeconômico da região foi 
frequente. A professora de português fez questão de apresentar o caderno das atividades de classe e o caderno de tarefa de casa de algumas delas, exemplificando os "bons" e os "nãobons"; os que acompanham, e os que não acompanham; os com família estruturada, e os que não. Todos os professores requeriam maior presença da família nas atividades escolares, principalmente nas tarefas de casa.

Havia alunos não-brasileiros nas duas turmas do segundo ano observadas. A professora das turmas, na aula de português, fez a dinâmica, como exposto, de apresentar os cadernos deles também, fazendo comentários sobre os rendimentos em sala e em casa deles. A distinção principal estava basicamente no rendimento, os que acompanham o cronograma e os que não acompanham. Durante a atividade de sala, a professora anda entre as fileiras tirando as dúvidas que vão surgindo, entre elas as dos alunos não-brasileiros. Observou-se o conhecimento de vocabulário da professora ao sacar as dúvidas de uma das crianças, de família argentina, considerada boa por ela por acompanhar relativamente bem o conteúdo, apesar de certas dificuldades de pronuncia e vocabulário.

Essa homogeneização do tratamento tendo em vista somente o cronograma de atividades como modelo diferenciador suscitou o questionamento sobre então quem seria o outro? Candau (2012, p.29 e 30) retoma a Skiliar e Dutchanzky (2000) para tratar a relação com o outro ou alteridade. Estes autores distinguem três formas em que se trata a alteridade: o outro como fonte de todo mal; o outro como sujeito pleno de um grupo cultural; e o outro como alguém a tolerar. No primeiro "modo de situar-se diante do outro, assume-se uma visão binaria e dicotômica. Uns são bons, os verdadeiros, os autênticos, os civilizados, os cultos, os defensores da liberdade e da paz. Os outros são maus, falsos, bárbaros, ignorantes, terroristas." $\mathrm{Na}$ educação, essa perspectiva se traduz na atribuição do fracasso escolar às características e origens sociais e culturais dos alunos que acabam sendo estereotipadas. $\mathrm{O}$ outro como sujeito pleno de um grupo cultural essencializa as diferenças, pois parte da concepção que os sujeitos fazem parte de uma comunidade homogênea de crenças e estilos. "Na educação esta posição pode se revestir de duas principais manifestações: uma entrada folclórica, caracterizada por um percurso turístico de costumes, e escolarizada que converte a diversidade cultural em um almanaque que engrossa a lista de festejos escolares a reivindicação como retorica legitimadora da autonomia institucional." (CANDAU, 2012, p. 31.). Finalmente, o outro como alguém a se tolerar, na educação, evita o pensamento focado nas relações de dominação que permeiam as culturas, buscando falso caráter conciliador. 
Gusmão (1999, p.42), estabelece que na concepção ocidental centrada na imparcialidade da ciência e no caráter evolucionista da humanidade, a relação com o outro está centrada falácia de que todos são herdeiros ao homem branco, racional, civilizado, masculino, adulto enquanto medida de todas as coisas. Desta maneira, “[...] a infância [...] tal como índios, mulheres, velhos e crianças são também, um “outro", estrangeiro no mundo dos adultos e assim, vistos como sujeitos inacabados da condição humana, cuja imagem sem reflexo cria a ilusão de uma sociedade sem espelhos.” (GUSMÃO, 1999, p.42, 43).

O outro, nesse meio escolar, é o que não se encaixa ao cronograma de conteúdos, é a negação da idealização feita pela ciência, no limite como sujeito de outro grupo cultural. Mas por que tantos outros? Seria um preceito desses professores? Ou uma estrutura da escola? A discussão sobre o currículo é central para essas indagações.

A Lei de Diretrizes e Bases de 1996 estabelece a obrigatoriedade da existência e estruturação do currículo nas escolas, estabelecendo conteúdos a serem abordados, que foram complementados pelos temas transversais já abordados.

Essa lei:

[...] estabelece uma logica disciplinar e uma organização do conhecimento por componentes curriculares, cuidando, inclusive, nela mesmas, e a partir dela, de determinar o que deve ser estudado na escola, de como os estudos devem ser organizados, realizados, e das condições sobre as quais os conteúdos devem ser ministrados. (PADILHA, 2004, p. 119)

Mais que o currículo nacional, o projeto-político-pedagógico (PPP), “como forma de melhor prever, organizar e avaliar as ações e relações que se estabelecem e que são tecidas no âmbito da escola" (PADILHA, 2004, p. 147) explicita melhor as relações sociais no interior da escola e suas relações com a região, pois "sua dimensão político-pedagógica caracteriza uma construção ativa e participativa dos diversos segmentos escolares [...]" (PADILHA, 2004, p. 147). Essa vinculação com a região, aliás, surgiu pelos comentários dos professores observados no campo, principalmente pela frequente menção à situação familiar das crianças e à situação da socioeconômica da região.

O PPP da escola em questão reconhece e se situa na região que está inserida, considerando a grande população do bairro e os problemas sociais que apresenta. Os professores destacaram que o bairro é fruto de duas ocupações urbanas que foram regularizadas e há uma terceira que está nesse processo. 
Contudo, a escola distancia-se de tal situação ao questionar sua função social na manutenção dos benefícios dos programas sociais do governo federal, separando-se do que ela chama de sistema que deveria exercer o papel de melhores condições de sustentação para as famílias; considerando como "acomodados" os que recebem o beneficio, sendo também negligentes na educação da criança, enviando-as à escola só para manutenção do auxílio.

Esse distanciamento está vinculado à exclusividade requerida pela escola no quesito ensino-aprendizagem. Em diversos momentos do texto, ela reivindica "a verdadeira função da escola", ou "a sua função primeira", não podendo ser "influenciadas por terceiros" que “destinaram a educação para outros finns". Essa exclusividade trás consequências, inclusive ao próprio ensino-aprendizagem, pois distancia o conteúdo ensinado da realidade sociocultural das crianças, mantendo a educação em um nível genérico de abstração como apresentado pelos professores observados.

Nesse sentido, assim como essa realidade sociocultural é marginalizada no conteúdo das aulas, os temas transversais também são, tanto pelo conteúdo da região requerido por eles para seu desenvolvimento, quanto pelo modo esporádico como são trabalhados, expressos no PPP, em projetos, feiras culturais, aulas culturais, passeios pedagógicos e palestras.

Entre esse processo de periodicidade das atividades culturais e na tentativa de integrálo ao cotidiano das aulas, a escola faz parte desde 2006 do Projeto Escolas Bilíngues de Fronteiras, que vem sendo implantado em escolas de fronteira com os países do Mercosul. Este projeto promove o intercambio de professores entre as escolas dos diferentes países (no caso Brasil-Argentina) para ministrarem aulas nas línguas dos países de origem. O projeto é acompanhado pela Secretaria Municipal de Educação, pelo MEC e pela UNILA, contato que permitiu a realização deste trabalho.

Por mais que os parâmetros curriculares nacionais, nos temas transversais e especificamente na pluralidade cultural, em todos os debates suscitados na sua elaboração e aplicação, estabeleça a relação cultura-educação sobre os vieses do multiculturalismo, como mencionado em Fleuri (2000, p.48 e 49) em máximo pela interculturalidade funcional no contexto de América Latina de Walsh $(2009$, p. 4) a sua presença cotidiana em sala de aula é fundamental pela sua urgência temática e para melhor aproximação na aprendizagem.

Cummins (2001, p.19) ao analisar turmas em escolas estadunidense permeadas pela questão bilíngue inglês-espanhol, defende que o professor deve atuar como elo entre macro- 
interactions e micro-interactions sociais, sendo definidores intermediários da primeira na segunda. Essa relação acontece de maneira hierárquica, dependendo em grande parte do/a professor/a de abordar determinadas temáticas em determinados formatos, no caso estudado pelo autor, estabelecendo o bilinguismo. Desta maneira, as marcas de alteridade estabelecidas em outros campos sociais de macro-interacions podem ser manejadas e suprimidas pelo/a professora/a nas micro-interactions do campo escolar, por meio da aproximação da identidade e empowerment do/a aluno/a nas situações escolar.

Porém, esse elo permitido pelo/a professor/a também pode estabelecer relações de dominação e homogeneização como foi observado no campo. A professora de português do segundo ano faz uma pequena oração todo começo de aula, se justificando: eu faço uma oração todo come de aula, porque sou católica, mas eu disse pra ele no primeiro dia de aula que quem não quiser fazer a oração não tem problema, só ficar quietinho de cabeça baixa e esperar em silêncio.

Essa abordagem claramente freiriana, vai muito além do bilinguismo. Pensando estritamente o pensamento fronteiriço a partir do exemplo de Anzaldúa também no inglêsespanhol, Mignolo (2003, p.343) propõe o plurilinguajamento, como elemento denunciativo da colonialidade do poder e do saber presente na língua gramatical imposta pelo Estado. Este plurilinguajamento é uma interação linguística que vai além da língua, transformado em um modo de viver na intersecção entre duas ou mais línguas, duas ou mais linguagens. (MIGNOLO, 2003: 358 e 359).

O plurilinguajamento foi expresso no campo por meio de um aluno apresentado pela professora de português do segundo ano na turma da tarde, como problemático, com grandes problemas de aprendizado e comportamento, morador de uma ocupação urbana da região, com família desestruturada e como descendente de paraguaios, que falam guarani. Em um pequeno dialogo durante a atividade de sala, ao me apresentar o caderno, perguntei se ele podia me falar algo em guarani (por sugestão da professora), e me ensinou vamos trabalhar (Jaha jamba'apo) e o questionei:

- Você gosta de falar português?

- Estou no Brasil tenho que falar português né.

- Mas qual você gosta mais de falar? 
- O Guarani, com meus tios, amigos, vizinhos. Meu pai não fala guarani comigo, mas eu gosto de falar.

- Mas você não fala o espanhol?

- Não, só o guarani e o português.

Esse diálogo trás várias questões a fim de conclusão. Por mais que os/as professore/as e, como apresentado, o projeto político pedagógico tenham conhecimento da realidade cultural e social da região e das crianças, eles/as somente as integram no ensino de maneira esporádica em atividades temáticas ou em tratamento específico no cotidiano, tratando esse outro como sujeito pleno de um grupo cultural a ser integrado ao programa.

Esse programa abordado de maneira neutra, imparcial na exclusividade ou função primeira da educação escolar requerida pelo PPP exerce o que Fleuri (2000, p. 48 e 49) aborda como educação monocultural, pois a ciência não é neutra, mas sim colonial na dominação gramatical do Estado sobre a língua em um processo linguajante.

\section{Conclusões}

Dentre as limitações do trabalho de campo realizadas em uma entre tantas escolas possíveis em Foz do Iguaçu, a proximidade entre o discurso dos/as professores/as e o PPP da escola, a marginalidade dos parâmetros curriculares no cotidiano das aulas e a centralidade do currículo na educação tem muito a dizer enquanto possibilidade de mudança da realidade na escola, sendo a principal contribuição desse trabalho, expor a realidade escolar para incentivar mais pesquisas nesse sentido em um plano de ação tanto de formação de professores como de mudança dos PPP das escolas.

\section{Referências}

CANDAU, Vera Maria. (org.). Sociedade multicultural e educação: tensões e desafios. In CANDAU, Vera Maria. (org.). Didática crítica intercultural: aproximações. Petrópolis, RJ; Vozes, 2012.

CUMMINS, Jim. Negotiating Identities: Education for Empowerment in a Siverse Society. California Association for Bilingual Education. Second Edition: 2001. 
MIGNOLO, Walter D. Bilinguajando o amor: pensando entre línguas. In: Histórias locais/Projetos globais: colonialidade, saberes subalternos e pensamento liminar. Tradução: Solange Ribeiro de Oliveira. Belo Horizonte: Editora da UFMG, 2003. p. 340-375.

FLEURI, Reginaldo Matias. Desafios à Educação Intercultural no Brasil. In. III Seminário Pesquisa em Educação Região Sul de Coordenadores de Pós-Graduação. Anais. Porto Alegre, 2000

FLEURI, Reginaldo Matias. Intercultura e Educação. Revista Brasileira de Educação $\mathrm{N}^{\circ}$ 23, p. $16-35,2003$

GUSMÃO, Neusa Maria Mendes de. Linguagem, cultura e alteridade: imagens do outro. Faculdade de Educação da UNICAMP. Cadernos de pesquisa, no 107, p. 41 - 78, julho/1999.

PADILHA, Paulo Roberto. Currículo intercultural: novos itinerários para a educação / Paulo Roberto Padilha - São Paulo : Cortez : Instituto Paulo Freire, 2004. - (Biblioteca freiriana: v.9)

WALSH, Catherine. Interculturalidad Crítica y Educación intercultural. Seminário Interculturalidad y Educación Intercultural, La Paz, 9 - 11 de março de 2009) 